\title{
Escape from floral herbivory by early flowering in Arabidopsis halleri subsp. gemmifera
}

\author{
Kawagoe, Tetsuhiro ; Kudoh, Hiroshi
}

\begin{abstract}
Natural selection on flowering phenology has been studied primarily in terms of plant-pollinator interactions and effects of abiotic conditions. Little is known, however, about geographic variation in other biotic factors such as herbivores and its consequence for differential selection on flowering phenology among populations. Here, we examine selection by floral herbivores on the flowering phenology of Arabidopsis halleri subsp. gemmifera using two adjacent populations with contrasting herbivory regimes. Intensive floral herbivory by the leaf beetle Phaedon brassicae occurs in one population, while the beetle is absent in another population. We tested the hypothesis that the two populations experience differential selection on flowering time that is attributable to the presence or absence of floral herbivory. A two-year field study showed that early flowering was favoured in the population under intensive floral herbivory, whereas selection for early flowering was not found in oneyear in the population where floral herbivory was absent. Selection for early flowering disappeared when the abundance of floral herbivores was artificially decreased in a field experiment. Thus, the heterogeneous distribution of P. brassicae was a major agent for differential selection on flowering time. However, flowering time did not differ between the two populations when plants were grown in the laboratory. The lack of genetic differentiation in flowering time may be explained by ongoing gene flow or recent invasion of P. brassicae. This study illustrates that the role of floral herbivory in shaping geographic variation in selection on flowering phenology may be more important than previously thought
\end{abstract}

DOI: https://doi.org/10.1007/s00442-010-1709-y

Posted at the Zurich Open Repository and Archive, University of Zurich

ZORA URL: https://doi.org/10.5167/uzh-156448

Journal Article

Published Version

Originally published at:

Kawagoe, Tetsuhiro; Kudoh, Hiroshi (2010). Escape from floral herbivory by early flowering in Arabidopsis halleri subsp. gemmifera. Oecologia, 164(3):713-720.

DOI: https://doi.org/10.1007/s00442-010-1709-y 


\title{
Escape from floral herbivory by early flowering in Arabidopsis halleri subsp. gemmifera
}

\author{
Tetsuhiro Kawagoe $\cdot$ Hiroshi Kudoh
}

Received: 9 January 2010/Accepted: 17 June 2010/Published online: 4 July 2010

(C) Springer-Verlag 2010

\begin{abstract}
Natural selection on flowering phenology has been studied primarily in terms of plant-pollinator interactions and effects of abiotic conditions. Little is known, however, about geographic variation in other biotic factors such as herbivores and its consequence for differential selection on flowering phenology among populations. Here, we examine selection by floral herbivores on the flowering phenology of Arabidopsis halleri subsp. gemmifera using two adjacent populations with contrasting herbivory regimes. Intensive floral herbivory by the leaf beetle Phaedon brassicae occurs in one population, while the beetle is absent in another population. We tested the hypothesis that the two populations experience differential selection on flowering time that is attributable to the presence or absence of floral herbivory. A two-year field study showed that early flowering was favoured in the population under intensive floral herbivory, whereas selection for early flowering was not found in one year in the population where floral herbivory was absent. Selection
\end{abstract}

Communicated by Jeff Karron.

T. Kawagoe $\cdot$ H. Kudoh

Department of Biology, Faculty of Science,

Kobe University, Nada, Kobe 657-8501, Japan

Present Address:

T. Kawagoe $(\square)$

Institute of Plant Biology, University of Zurich,

Zollikerstrasse 107, 8008 Zurich, Switzerland

e-mail: kawagoe.t@access.uzh.ch

Present Address:

H. Kudoh

Center for Ecological Research,

Kyoto University, Otsu, Shiga 570-2113, Japan

e-mail: kudoh@ecology.kyoto-u.ac.jp for early flowering disappeared when the abundance of floral herbivores was artificially decreased in a field experiment. Thus, the heterogeneous distribution of $P$. brassicae was a major agent for differential selection on flowering time. However, flowering time did not differ between the two populations when plants were grown in the laboratory. The lack of genetic differentiation in flowering time may be explained by ongoing gene flow or recent invasion of $P$. brassicae. This study illustrates that the role of floral herbivory in shaping geographic variation in selection on flowering phenology may be more important than previously thought.

Keywords Divergent selection - Florivory · Flowering time $\cdot$ Phaedon brassicae $\cdot$ Phenology

\section{Introduction}

Flowering phenology is a major determinant of plant reproductive success. Flowers that open at suboptimal periods may suffer from low visitation by pollinators (O’Neil 1999; Aizen 2003; Morinaga et al. 2003) or from severe abiotic conditions (Stinson 2004). A large number of studies on the ecology and evolution of flowering phenology have focused on consequences of plant-pollinator interactions and abiotic conditions (for reviews, see Rathcke and Lacey 1985; Elzinga et al. 2007; Strauss and Whittall 2007). These studies suggest that natural selection favours flowering phenologies that maximise plant reproductive success.

Recently, ecologists have found that natural selection on flowering phenology and other floral traits is mediated by natural enemies such as herbivores (Biere and Honders 1996; Brody 1997; Juenger and Bergelson 1998; Strauss 
and Irwin 2004; Elzinga et al. 2007; Kolb et al. 2007; Strauss and Whittall 2007; Ehrlén and Münzbergová 2009). For instance, foliar herbivory can affect floral traits such as floral display and flowering time (Strauss et al. 1996; Mothershead and Marquis 2000; Thomson et al. 2004; Brody et al. 2007; Suárez et al. 2009). Floral herbivory, or florivory, has also received increased attention as an important determinant of plant reproduction for the following reasons (Breedlove and Ehrlich 1968; McCall and Irwin 2006). First, floral herbivory affects the abundance and appearance of flowers, and may alter patterns of pollinator attraction and pollen movements (Krupnick and Weis 1999; Krupnick et al. 1999; Leavitt and Robertson 2006; Penet et al. 2009). Second, floral herbivory may directly reduce the availability of reproductive organs that would otherwise produce mature seeds (McCall 2008). Finally, temporal changes in the intensity of floral herbivory have been observed (Evans et al. 1989; EnglishLoeb and Karban 1992; Bishop and Schemske 1998; Pilson 2000; Mahoro 2002; Juenger et al. 2005; Tarayre et al. 2007; Oguro and Sakai 2009), and this can serve as a source of selection on flowering time to avoid floral herbivory (Elzinga et al. 2007).

Compared to pollinator-mediated selection, however, our understanding of the influences of floral herbivory on the ecology and evolution of flowering phenology is still limited. As the abundances and compositions of herbivore communities can vary geographically (Lewinsohn et al. 2005), the spatial heterogeneity in floral herbivory can be an important agent for differential selection on flowering phenology. Although a few studies have investigated variation in floral herbivory among populations and its consequences for selection on flowering phenology (Sandring et al. 2007; Kelly et al. 2008; Mosleh Arany et al. 2009), confounding factors, either biotic or abiotic, could have also affected the observed patterns of selection because distantly located populations that differed in abiotic and biotic environments were often studied. It is necessary, therefore, to study the role of floral herbivory in determining selection on flowering time among populations with similar environmental conditions.

In this study, we examined phenotypic selection on flowering time via female fitness mediated by floral herbivory in Arabidopsis halleri (L.) O'Kane \& Al-Shehbaz subsp. gemmifera (Matsum.) O'Kane \& Al-Shehbaz (Brassicaceae). We studied two populations that differ considerably in the intensity of floral herbivory. The leaf beetle Phaedon brassicae Baly (Coleoptera, Chrysomelidae) is abundant and intensively damages flowers and flower buds in one population (Fig. 1), whereas the beetle is absent in the adjacent population. As the two populations are in close proximity, this system provides a unique opportunity to study differential selection on flowering time under contrasting floral herbivory regimes with similar abiotic conditions. By combining a field census and experiments, we addressed the following questions:

1. Does phenotypic selection on flowering time via female fitness differ between the two populations under contrasting floral herbivory regimes?

2. Is selection on flowering time altered when the abundance of $P$. brassicae is manipulated in the field?

3. Has flowering time been differentiated genetically between the two populations?

\section{Materials and methods}

\section{Study system}

Arabidopsis halleri subsp. gemmifera is a self-incompatible, perennial herb that grows in moist habitats in Japan. Flowering starts in early April, and fruits mature in June. A mature fruit typically contains 10-15 seeds. After flowering, plants produce new rosettes and grow vegetatively for the rest of the year. They then overwinter as rosettes. Study populations are located in Hyogo Prefecture in the western part of Japan $\left(35^{\circ} 10^{\prime} \mathrm{N}, 134^{\circ} 93^{\prime} \mathrm{E}\right.$, $200 \mathrm{~m}$ in altitude). The two populations, referred to as the $\mathrm{OM}$ and $\mathrm{MZ}$ populations, respectively, are separated by only $3 \mathrm{~km}$, and plants grow along the two small, shallow creeks running through open forests on the south-facing slope of a hill. Thus, abiotic conditions such as climate, light and water availability are similar between the two populations.

The chrysomelid leaf beetle Phaedon brassicae severely damages plants in the OM population (Fig. 1). This beetle is a crucifer-feeding specialist that is known to be a pest for Brassica and Raphanus crops. However, the beetle is absent in the MZ population. Moreover, of the 40 populations of A. halleri subsp. gemmifera across Japan that we surveyed, $P$. brassicae was found in only two populations (OM and one closely located population, T. Kawagoe, unpublished data). In the OM population, A. halleri subsp. gemmifera is the only host plant of $P$. brassicae. Larvae are most abundant in the flowering season in spring, and lower numbers of adults and larvae feed on leaf tissues in summer and autumn. Although other insects such as larvae of the small white butterfly Pieris napi L. and the moth Plutella xylostella L. feed on A. halleri subsp. gemmifera in both populations, their abundances are quite low throughout the year, and floral herbivory by these insects is extremely rare; less than $1 \%$ of the plants were infested by these lepidopteran larvae when the plants were censused in the flowering season. Thus, their effects on plant fitness were minimal at the study sites. 
Fig. 1 Photographs showing the effects of larvae of $P$. brassicae on flowers and buds of $A$. halleri subsp. gemmifera. a Heavily damaged inflorescences; larvae are indicated by arrows. AM, apical meristem. b Enlargement showing a larva feeding on flowers
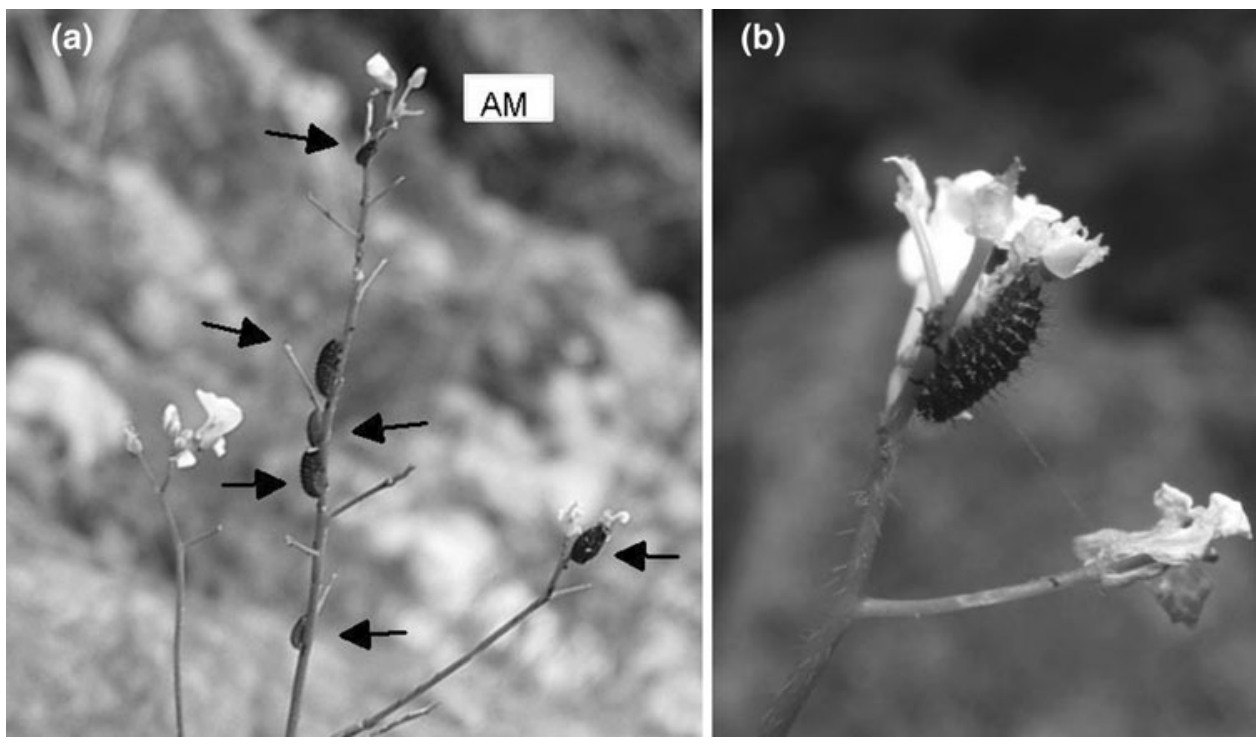

Phenotypic selection in the field

We conducted a field census for two flowering seasons (2007 and 2008) in both populations to examine the relationship between flowering time and fruit production. We established four and three rectangular plots in the $\mathrm{OM}$ and MZ populations, respectively, within which plants were marked individually. These plots were $1 \mathrm{~m}$ in width and were set to cover plants on both sides of the creek. The length of a plot varied from 3 to $10 \mathrm{~m}$ depending on how far the plants occurred from the creek. These plots were parallel to each other, and the distance between the nearest plots was greater than $20 \mathrm{~m}$. We measured the rosette diameter of each plant prior to the flowering season. During the flowering season from April to May, the first day of flowering, hereafter referred to as the flowering time, was recorded once a week for each plant. The number of herbivorous insects on each plant was also counted every week. After the flowering season, we counted the number of mature fruits and fruit remains from which seeds had been released. We could not examine seed production because it was difficult to prevent spontaneous seed release from fruits while allowing herbivores to access flowers and young fruits. Plants that did not flower were excluded from the analysis. The numbers of plants used for the analysis were 312 and 217 in the OM population and 198 and 216 in the MZ population in 2007 and 2008, respectively.

\section{Manipulation of floral herbivory in the field}

To test the hypothesis that floral herbivory by $P$. brassicae affects natural selection on flowering time, a field experiment was conducted in which the abundance of $P$. brassicae was manipulated using an insecticide. Because there was substantial variation in size and age among naturally grown plants, we used plants derived from seeds for the experiment to reduce variation in plant age. The experiment was carried out in the $\mathrm{OM}$ population because $P$. brassicae was absent in the $\mathrm{MZ}$ population and thus herbivore-mediated selection could not be studied. More than 30 seeds were collected from each of 24 maternal plants outside of the census plots in the OM population in June 2006. The maternal plants were at least $10 \mathrm{~m}$ apart, and the most distant maternal plants were separated by $300 \mathrm{~m}$. As primary seed dispersal depends on gravity, the probability of sampling kin individuals was minimized by this sampling strategy. The seeds were sown in the laboratory. When the seeds germinated, the seedlings were grown in a growth chamber with $16 \mathrm{~h}$ days at $25^{\circ} \mathrm{C}$ and $8 \mathrm{~h}$ nights at $15^{\circ} \mathrm{C}$. The intensity of fluorescent light in the chamber was ca. $200 \mu \mathrm{mol} \mathrm{m} \mathrm{m}^{-2} \mathrm{~s}^{-1}$. After two months of growth, four plants for each of 24 maternal half-sib families (96 plants in total) were randomly selected and transplanted into the OM population on 5 October 2006. We established four plots that were separated by at least $30 \mathrm{~m}$. Each plot consisted of 24 plants arranged in a $4 \times 6$ square-grid pattern with a $0.1 \mathrm{~m}$ interval between the nearest plants. Half of the plants in each plot were assigned to the insecticide treatment, and the other half were designated as the control. We applied $1 \mathrm{~g}$ of a slow-acting insecticide (Oltran, Sumitomo Chemical Garden Products Inc., Tokyo, Japan) every two months. In addition, herbivorous insects on insecticide-treated plants were removed by hand when they were found. During the following spring, rosette diameter was measured before flowering. The first day of flowering was recorded and the number of $P$. brassicae on each plant was counted once a week. The numbers of mature fruits and fruit remains were counted 
for each plant after the flowering season. Four control plants and two insecticide-treated plants did not flower. The remaining 44 and 46 plants in the control and insecticide treatments, respectively, were used for analysis (see below). During the experiment, plants were supplied once a month with a 1,000-fold solution of a commercially available nutrient (Hyponex; the concentrations of $\mathrm{N}, \mathrm{P}$ and $\mathrm{K}$ were 6,10 and $5 \%$, respectively; Hyponex Japan Corp., Osaka, Japan).

Genetic difference in flowering time between the two populations

To test whether flowering time was genetically differentiated between the two populations, we performed a common garden experiment in which plants originating from both populations were grown under the same conditions in the laboratory. Seeds were collected from 24 maternal plants in each population and germinated in the laboratory (note that the OM maternal plants used in this experiment were different from those used in the field experiment described above). Two plants for each maternal half-sib family were used for the experiment $(2$ plants $\times 24$ mothers $\times 2$ populations $=96$ plants in total). Plants were randomly assigned to one of four trays, and each tray contained 24 plants. Plants were grown individually in $7.5 \mathrm{~cm}$ diameter plastic pots in a growth chamber with $16 \mathrm{~h}$ days at $25^{\circ} \mathrm{C}$ and $8 \mathrm{~h}$ nights at $15^{\circ} \mathrm{C}$. After three months of growth at the rosette stage, the plants were vernalised for two months at $5^{\circ} \mathrm{C}$ with a day length of $10 \mathrm{~h}$. Rosette diameter was measured after vernalisation, and then the plants were allowed to flower under a regime with $16 \mathrm{~h}$ days at $20^{\circ} \mathrm{C}$ and $8 \mathrm{~h}$ nights at $10^{\circ} \mathrm{C}$. This growth condition simulated vegetative growth in autumn, overwintering, and flowering during the following spring in the field. During the experiment, the positions of the trays in the growth chamber were rotated every 3-5 days to minimise microenvironmental variation among trays. The first day of flowering was recorded every 1-2 days. Flowering time was considered to be the days to flowering after vernalisation. Because the species is self-incompatible and flowers were not pollinated in this experiment, we could not measure fruit production. Instead, the number of peduncles remaining on flowering stems was counted as a measure of flower production. Flower production was a good predictor of female fitness because fruit set was high $(>80 \%)$ in the field unless the flower was consumed by herbivores. Plants were supplied with a 1,000-fold diluted solution of Hyponex once a month. We performed the common garden experiment instead of a field reciprocal experiment because the latter requires plants to flower in the field, which would have caused unwanted genetic contamination of natural populations.
Statistical analysis

All statistical analyses were carried out using the $\mathrm{R}$ statistical package v.2.9.0 (R Development Core Team 2009). We performed a multivariate phenotypic selection analysis on flowering time (days to flowering) in natural populations (Lande and Arnold 1983), in which fruit production was a response variable and flowering time and rosette diameter were included as independent variables. The number of fruits was normalised by dividing individual values by a mean. Independent variables were standardised to have a mean of zero and a variance of unity. The number of fruits produced was not normally distributed but was highly zeroinflated. Thus, we estimated partial regression coefficients, or selection gradients, in multivariate selection models by the bootstrap method, with resampling performed 10,000 times (Crawley 2007). The means and 95\% confidence intervals of coefficients were estimated to test whether regression coefficients deviated significantly from zero. We also examined nonlinear selection on flowering time by the bootstrap method to test whether stabilising or disruptive selection occurs. However, neither a fitness peak nor a fitness valley appeared within the flowering time range we observed. For this reason, the results of quadratic selection analysis are not shown in this paper.

The same method was applied to estimate selection gradients for flowering time in the field experiment in which insects were artificially removed. Bootstrap resampling was performed separately in the control and insecticide treatments.

In the common garden experiment, flowering time was compared between plants from the two populations by generalised linear mixed effects models (the lmer function implemented in R), in which population and rosette diameter were included as fixed factors and mother plants and block were random factors. A log-likelihood test was performed to compare models with and without the population term.

\section{Results}

Phenotypic selection in the field

In the OM population under intensive floral herbivory by $P$. brassicae, some plants started to flower before the emergence of $P$. brassicae, whereas a large proportion of plants did so after $P$. brassicae emerged (Fig. 2). The selection gradient on flowering time was negative and deviated significantly from zero in each of the two years (Table 1). Thus, early flowering was favoured for two years in the OM population. In the MZ population, where $P$. brassicae was absent, early flowering was favuored in 
Fig. 2 Temporal patterns of number of $A$. halleri subsp. gemmifera plants that started flowering at the day of the census (plants per day; bars) and number of $P$. brassicae larvae per plant (mean $\pm \mathrm{SE}$; lines) in the OM population in a 2007; c 2008. Flowering times of plants in the $\mathrm{MZ}$ population in b 2007 and d 2008.

$P$. brassicae was absent in the $\mathrm{MZ}$ population

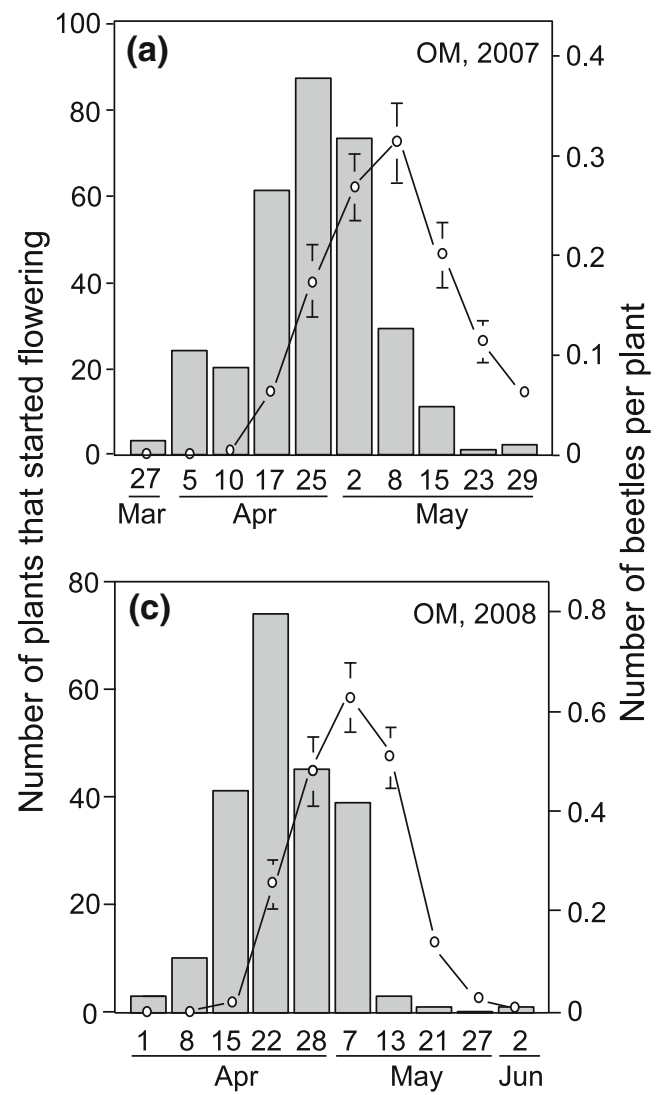

2007 but selection was not significant in 2008 (Table 1). Phenotypic selection for larger plants was significantly positive in both populations for the two years (Table 1).

Manipulation of floral herbivory in the field

Plants suffered from floral herbivory in the control treatment, whereas the abundance of $P$. brassicae was decreased in the insecticide treatment (Fig. 3). Insects were removed from the insecticide-treated plants by hand after counting them, so damage to plants in the insecticide treatment was much lower than to those in the control.

Selection for early flowering was significant in the control treatment, which was consistent with the results of the field census (Table 2). In the insecticide treatment, flowering time was not significantly correlated with fruit production (Table 2). Therefore, floral herbivory by $P$. brassicae altered phenotypic selection on flowering time.

Genetic difference in flowering time between the two populations

Flowering time did not differ significantly between the two populations when the plants were grown under the same laboratory conditions (Fig. 4, log-likelihood test of mixed effects models with and without the population term,
Table 1 Selection gradients for flowering time and rosette size with the number of fruits as a response variable

\begin{tabular}{llll}
\hline Population and year & Estimate & Flowering time & Rosette size \\
\hline OM 2007 & Mean & $\mathbf{- 0 . 3 0 3}$ & $\mathbf{0 . 4 3 2}$ \\
& SD & 0.069 & 0.109 \\
& $95 \%$ CI & $-0.439,-0.169$ & $0.229,0.653$ \\
OM 2008 & Mean & $\mathbf{- 0 . 3 8 9}$ & $\mathbf{0 . 7 9 1}$ \\
& SD & 0.146 & 0.236 \\
MZ 2007 & $95 \%$ CI & $-0.699,-0.122$ & $0.379,1.310$ \\
& Mean & $\mathbf{- 0 . 2 9 3}$ & $\mathbf{0 . 5 8 3}$ \\
& SD & 0.077 & 0.131 \\
MZ 2008 & $95 \%$ CI & $-0.456,-0.153$ & $0.329,0.849$ \\
& Mean & -0.250 & $\mathbf{0 . 9 4 5}$ \\
& SD & 0.193 & 0.363 \\
& $95 \%$ CI & $-0.581,0.178$ & $0.379,1.758$ \\
\hline
\end{tabular}

Means, SDs, and $95 \%$ confidence intervals (CI) of selection gradients estimated by the bootstrap method are shown. Selection gradients for which $95 \%$ CIs do not include zero are indicated in bold. Two values for $95 \%$ CIs represent lower and upper limits

$P=0.9$ ). If flowering-time variation in natural populations was determined only by environmental factors, the variation would decrease when the plants are grown under the same homogeneous laboratory conditions. However, we found that flowering-time variation in the laboratory was 


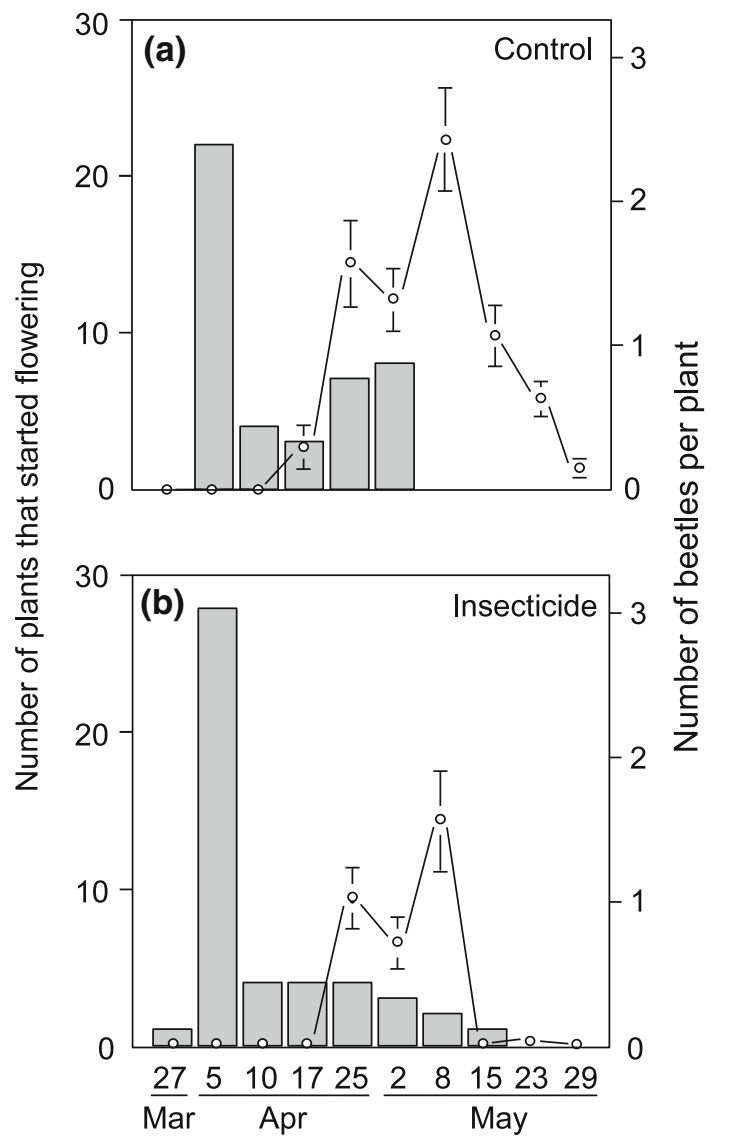

Fig. 3 Temporal patterns of number of A. halleri subsp. gemmifera plants that started flowering at the day of the census (plants per day; bars) and the abundance of the leaf beetle $P$. brassicae larvae (mean \pm SE per plant; lines) in the $\mathbf{a}$ control and $\mathbf{b}$ insecticide treatments. Insects found in the insecticide treatment were removed by hand after counting

Table 2 Selection gradients for flowering time and rosette size with the number of fruits as a response variable in the field experiment in which the abundance of floral herbivores was manipulated using insecticide

\begin{tabular}{llcc}
\hline Treatment & Estimate & Flowering time & Rosette size \\
\hline Control & Mean & $\mathbf{- 0 . 2 6 1}$ & 0.082 \\
& SD & 0.116 & 0.108 \\
& $95 \%$ CI & $-0.479,-0.019$ & $-0.145,0.286$ \\
Insecticide & Mean & -0.041 & $\mathbf{0 . 2 3 8}$ \\
& SD & 0.12 & 0.094 \\
& $95 \%$ CI & $-0.308,0.163$ & $0.055,0.425$
\end{tabular}

See Table 1 for details

comparable to that in natural populations; the difference between the earliest and latest flowering time was 59 days in the laboratory, and 38-63 days in the two populations over the two years. Levene's test for equality of variances in flowering time in the laboratory and under natural conditions was not significant for three of four comparisons:

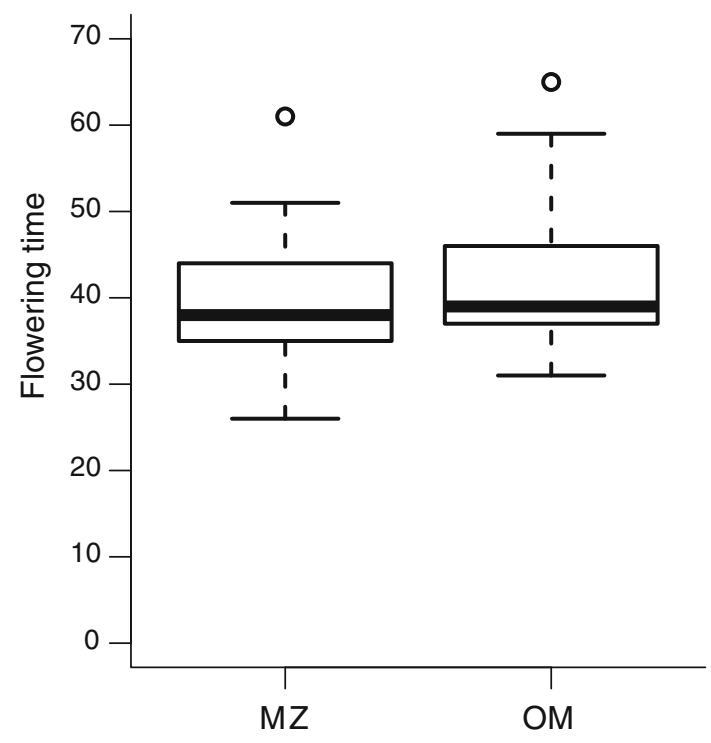

Fig. 4 Flowering times of plants from two A. halleri subsp. gemmifera populations grown under common laboratory conditions. Flowering time is considered to be days to flowering after vernalisation

laboratory vs. $2008 \mathrm{MZ}, F=0.0003, P=0.99$; laboratory vs. $2007 \mathrm{MZ}, F=0.14, P=0.71$; laboratory vs. 2008 $\mathrm{OM}, F=1.57, P=0.21$; whereas the test result was significant after Bonferroni correction in the comparison of laboratory vs. $2007 \mathrm{OM}, F=8.54, P=0.0036$.

\section{Discussion}

Phenotypic selection on flowering time mediated by floral herbivory

Our study showed that phenotypic selection on flowering time via female fitness differed between the two neighbouring populations subjected to contrasting herbivory regimes. Early flowering was favoured in each of the two years in the OM population, which received intensive floral herbivory from $P$. brassicae. In the MZ population, where $P$. brassicae was absent, early flowering was favoured in only one year (2007), and selection was not significant in the other year (2008). The field experiment also showed that selection for early flowering was weakened when the abundance of $P$. brassicae was artificially decreased. These results support the hypothesis that natural selection on flowering time is mediated by floral herbivory from $P$. brassicae. Furthermore, although $P$. brassicae consumes flowers and flower buds, they do not feed on developing fruits, probably because of the increased toughness of the fruits in later stages. This feeding pattern of $P$. brassicae gives a great fitness advantage to plants that flower and develop fruits prior to the emergence of 
$P$. brassicae. We also found that the temporal change in the abundance of $P$. brassicae did not coincide with the frequency distribution of flowering time (Fig. 2). Therefore, the temporal change in the intensity of floral herbivory was the source of selection for early flowering. Florivory by $P$. brassicae has been intense in the OM population since we started field studies in 2005, while $P$. brassicae has been absent from the MZ population since 2006 (T. Kawagoe et al., unpublished work). Importantly, the dispersal ability of $P$. brassicae appears to be strongly limited because adults are flightless. Thus, the two populations have been under contrasting florivory regimes for at least four years.

The lower fitness of plants that flowered later in the flowering season could also be explained by pollinatormediated selection. For instance, a decrease in pollinator visits later in the flowering season may result in the negative correlation between flowering time and fruit production. However, this is unlikely to be the case, because selection for early flowering disappeared when the herbivores were removed. This means that late-opening flowers were able to receive sufficient pollinator visits to produce fruits in the $\mathrm{OM}$ population unless they were consumed by $P$. brassicae. Furthermore, the mean fruit set for flowers that were not consumed by $P$. brassicae was higher than $85 \%$ and did not decrease during the flowering season in both populations (logistic regression of fruit set on flowering time, $P=0.9$ in $\mathrm{OM} ; P=0.1$ in $\mathrm{MZ}$ ). Thus, pollinator limitation cannot explain the decrease in fruit production in the late period of the flowering season. Although the strength and the direction of selection on floral traits imposed by pollinators and herbivores can differ and are sometimes antagonistic (Strauss and Whittall 2007; Parachnowitsch and Caruso 2008), our results did not show any evidence of conflicting selection imposed by pollinators and floral herbivores. We conclude that flower predation is the most influential factor in both fruit production and differential selection on flowering time between the two populations.

No evidence of genetic differentiation

between populations

The results of the laboratory experiment showed that flowering time was not differentiated genetically between the two populations. This contrasts with the results of the field study, which showed differential phenotypic selection on flowering time. There are several possible explanations for this inconsistency. First, plant populations may not be able to respond to differential selection because of the lack of genetic variation in flowering time. Second, the influences of demographic processes such as gene flow and the recent shared ancestry of the two populations may overwhelm that of contemporary natural selection. Third, differential selection mediated by floral herbivory may have begun to operate recently, so the populations did not have enough time to diverge genetically. The first hypothesis of a lack of genetic variation is less likely, because the variance in flowering time under the laboratory conditions was comparable to the flowering-time variation in the field for three out of four comparisons. Some of this variation is thus likely to be genetic, unless there was a considerable maternal environment effect. We think that the second or third scenario is more plausible for explaining the lack of genetic differentiation in flowering time. A previous study found weak or no evidence of differentiation in 11 microsatellite loci, a nuclear gene, and a highly variable chloroplast intergenic region between the two populations (T. Kawagoe and H. Kudoh, unpublished). Therefore, either the two populations have diverged recently from an ancestral population, or they have been connected by intensive gene flow. Furthermore, the absence of $P$. brassicae in all but one neighbouring population in this region (T. Kawagoe, personal observation) indicates that $P$. brassicae has invaded the OM population recently. If this is true, differential selection may have initiated very recently. The distribution patterns and long-term population dynamics of floral herbivores will be valuable for predicting the evolution of flowering time in local populations.

\section{Conclusions}

Although geographic variation in herbivore assemblages is well known, our understanding of variation in floral herbivory among natural populations and its consequences for selection on flowering phenology is still limited. We showed that closely located plant populations experienced differential phenotypic selection on flowering time mediated by the spatial heterogeneity of floral herbivory. Influences of geographic variation in floral herbivory regimes on differential selection on flowering phenology may be more important than previously thought, and floral herbivory can form a geographic mosaic of selection on flowering schedule.

Acknowledgments The authors thank J. Sugisaka for help in transplanting, and two anonymous reviewers whose comments greatly improved the manuscript. This study was supported by a Japan Society for the Promotion of Science Research Fellowship for Young Scientists to T. Kawagoe and grants-in-aid (MEXT, Japan; Scientific Research (B), 20370012, Special Research on Priority Areas, $119043010)$ to H. Kudoh, and by Global COE Program A06 of Kyoto University. This work complies with the current laws of Japan, in which the experiments were performed.

\section{References}

Aizen MA (2003) Influences of animal pollination and seed dispersal on winter flowering in a temperate mistletoe. Ecology 84:26132627 
Biere A, Honders SJ (1996) Impact of flowering phenology of Silene alba and $S$. dioica on susceptibility to fungal infection and seed predation. Oikos 77:467-480

Bishop JG, Schemske DW (1998) Variation in flowering phenology and its consequences for lupines colonizing Mount St. Helens. Ecology 79:534-546

Breedlove DE, Ehrlich PR (1968) Plant-herbivore coevolution: lupines and lycaenids. Science 162:671-672

Brody AK (1997) Effects of pollinators, herbivores, and seed predators on flowering phenology. Ecology 78:1624-1631

Brody AK, Price MV, Waser NM (2007) Life-history consequences of vegetative damage in scarlet gilia, a monocarpic plant. Oikos 116:975-985

Crawley MJ (2007) The R book. Wiley, Chichester

Ehrlén J, Münzbergová Z (2009) Timing of flowering: opposed selection on different fitness components and trait covariation. Am Nat 173:819-830

Elzinga JA, Atlan A, Biere A, Gigord L, Weis AE, Bernasconi G (2007) Time after time: flowering phenology and biotic interactions. Trends Ecol Evol 22:432-439

English-Loeb GM, Karban R (1992) Consequences of variation in flowering phenology for seed head herbivory and reproductive success in Erigeron glaucus (Compositae). Oecologia 89:588595

Evans EW, Smith CC, Gendron RP (1989) Timing of reproduction in a prairie legume: seasonal impacts of insects consuming flowers and seeds. Oecologia 78:220-230

Juenger T, Bergelson J (1998) Pairwise versus diffuse natural selection and the multiple herbivores of scarlet gilia, Ipomopsis aggregata. Evolution 52:1583-1592

Juenger T, Morton TC, Miller RE, Bergelson J (2005) Scarlet gilia resistance to insect herbivory: the effects of early season browsing, plant apparency, and phytochemistry on patterns of seed fly attack. Evol Ecol 19:79-101

Kelly D, Ladley JJ, Robertson AW, Crowfoot L (2008) Flower predation by Zelleria maculata (Lepidoptera) on Peraxilla mistletoes: effects of latitude and fragmentation, and impact on fruit set. New Zeal J Ecol 32:186-196

Kolb A, Ehrlén J, Eriksson O (2007) Ecological and evolutionary consequences of spatial and temporal variation in pre-dispersal seed predation. Perspect Plant Ecol Evol Syst 9:79-100

Krupnick GA, Weis AE (1999) The effect of floral herbivory on male and female reproductive success in Isomeris arborea. Ecology 80:135-149

Krupnick GA, Weis AE, Campbell DR (1999) The consequences of floral herbivory for pollinator service to Isomeris arborea. Ecology 80:125-134

Lande R, Arnold SJ (1983) The measurement of selection on correlated characters. Evolution 37:1210-1226

Leavitt H, Robertson IC (2006) Petal herbivory by chrysomelid beetles (Phyllotreta sp.) is detrimental to pollination and seed production in Lepidium papilliferum (Brassicaceae). Ecol Entomol 31:657-660

Lewinsohn TM, Novotny V, Basset Y (2005) Insects on plants: diversity of herbivore assemblages revisited. Ann Rev Ecol Evol Syst 36:597-620

Mahoro S (2002) Individual flowering schedule, fruit set, and flower and seed predation in Vaccinium hirtum Thunb. (Ericaceae). Can J Bot 80:82-92
McCall AC (2008) Florivory affects pollinator visitation and female fitness in Nemophila menziesii. Oecologia 155:729-737

McCall AC, Irwin RE (2006) Florivory: the intersection of pollination and herbivory. Ecol Lett 9:1351-1365

Morinaga SI, Tsuji K, Sakai S (2003) Consequences of differences in flowering date on seed production in Heloniopsis orientalis (Liliaceae). Am J Bot 90:1153-1158

Mosleh Arany A, de Jong TJ, van der Meijden E (2009) Herbivory and local genetic differentiation in natural populations of Arabidopsis thaliana (Brassicaceae). Plant Ecol 201:651-659

Mothershead K, Marquis RJ (2000) Fitness impacts of herbivory through indirect effects on plant-pollinator interactions in Oenothera macrocarpa. Ecology 81:30-40

O'Neil P (1999) Selection on flowering time: an adaptive fitness surface for nonexistent character combinations. Ecology 80:806820

Oguro M, Sakai S (2009) Floral herbivory at different stages of flower development changes reproduction in Iris gracilipes (Iridaceae). Plant Ecol 202:221-234

Parachnowitsch AL, Caruso CM (2008) Predispersal seed herbivores, not pollinators, exert selection on floral traits via female fitness. Ecology 89:1802-1810

Penet L, Collin CL, Ashman TL (2009) Florivory increases selfing: an experimental study in the wild strawberry, Fragaria virginiana. Plant Biol 11:38-45

Pilson D (2000) Herbivory and natural selection on flowering phenology in wild sunflower, Helianthus annuus. Oecologia 122:72-82

Rathcke B, Lacey EP (1985) Phenological patterns of terrestrial plants. Annu Rev Ecol Syst 16:179-214

Sandring S, Riihimäki MA, Savolainen O, Ågren J (2007) Selection on flowering time and floral display in an alpine and a lowland population of Arabidopsis lyrata. J Evol Biol 20:558-567

Stinson AJ (2004) Natural selection favors rapid reproductive phenology in Potentilla pulcherrima (Rosaceae) at opposite ends of a subalpine snowmelt gradient. Am J Bot 91:531-539

Strauss SY, Irwin RE (2004) Ecological and evolutionary consequences of multispecies plant-animal interactions. Annu Rev Ecol Evol Syst 35:435-466

Strauss SY, Whittall JB (2007) Non-pollinator agents of selection on floral traits. In: Harder LD, Barrett SCH (eds) Ecology and evolution of flowers. Oxford University Press, Oxford, pp 120 138

Strauss SY, Conner JK, Rush SL (1996) Foliar herbivory affects floral characters and plant attractiveness to pollinators: implications for male and female plant fitness. Am Nat 147:1098-1107

Suárez LH, Gonzáles WL, Gianoli E (2009) Foliar damage modifies floral attractiveness to pollinators in Alstroemeria exerens. Evol Ecol 23:545-555

Tarayre M, Bowman G, Schermann-Legionnet A, Barat M, Atlan A (2007) Flowering phenology of Ulex europaeus: ecological consequences of variation within and among populations. Evol Ecol 21:395-409

R Development Core Team (2009) R: a language and environment for statistical computing. R Foundation for Statistical Computing, Vienna (see http://www.R-project.org)

Thomson VP, Nicotra AB, Cunningham SA (2004) Herbivory differentially affects male and female reproductive traits of Cucumis sativus. Plant Biol 6:621-628 